\title{
Aspects of Türk İşaret Dili (Turkish Sign Language)
}

\author{
Ulrike Zeshan \\ Research Centre for Linguistic Typology, La Trobe University, Melbourne \\ \& Max-Planck-Institute for Psycholinguistics, Nijmegen
}

\begin{abstract}
This article provides a first overview of some striking grammatical structures in Türk İşaret Dili (Turkish Sign Language, TID), the sign language used by the Deaf community in Turkey. The data are described with a typological perspective in mind, focusing on aspects of TID grammar that are typologically unusual across sign languages. After giving an overview of the historical, sociolinguistic and educational background of TID and the language community using this sign language, five domains of TID grammar are investigated in detail. These include a movement derivation signalling completive aspect, three types of nonmanual negation headshake, backward head tilt, and puffed cheeks — and their distribution, cliticization of the negator NOT to a preceding predicate host sign, an honorific wholeentity classifier used to refer to humans, and a question particle, its history and current status in the language. A final evaluation points out the significance of these data for sign language research and looks at perspectives for a deeper understanding of the language and its history.
\end{abstract}

Keywords: Turkish Sign Language, Turkey, language typology, nonmanual marking, classifiers, clitics, history of sign language

\section{The language and its users}

Türk İşaret Dili (Turkish Sign Language, TID) is the sign language used in Deaf communities in Turkey. So far the available evidence suggests that the language is used all over Turkey, with some regional dialectal variation, mainly in the lexicon. Deaf people in Turkey consistently report being able to communicate quite easily with Deaf people from various other parts of Turkey. By contrast, they usually have much difficulty communicating with Deaf visitors from abroad, such as Deaf Europeans or Americans. The apparent linguistic unity is paralleled, and probably reinforced, by the social and political organization of the community (see below), which involves regular meetings of Deaf people from all regions of Turkey, but not from other countries. 
Similarly, contact with sign languages from abroad is quite limited, and there is currently no evidence to suggest that TID has developed on the basis of another sign language or has been under heavy influence from another sign language during its history. In other words, we have no reason to assume, either on historical or on linguistic evidence, that TID is anything but a truly indigenous sign language.

The data presented here are drawn from TID varieties in western and central Turkey, which are similar enough to be considered dialects. Reports from Deaf informants suggest that varieties in eastern Turkey seem to be more distinct, possibly including a greater influence of home signing. However, there has not been any linguistic study of these sign language varieties. More marked differences would be due to the general lack in infrastructure that characterizes eastern Turkey, with several factors making the sign language situation more unstable than in the rest of the country. These include a lesser population density, with fewer and more recent urban centers, and a delayed development of infrastructure serving the Deaf community, such as primary and secondary schools for the Deaf. It is characteristic of the situation that the first larger Deaf schools in Turkey were founded in Istanbul and Izmir in the western part of the country.

Nevertheless, Turkey now has Deaf clubs and associations, as well as specialized schools for the Deaf, in all parts of the country. The Deaf community is organized in a centralized way. All clubs and associations must be associated to the Turkish Federation of the Deaf (Türkiye İşitme Engelliler Milli Federasyonu), whose head office is in Istanbul. The Federation has a managing board consisting of seven members who are elected during one of the national conventions, usually a sports event. Every association has the right to nominate a few of its members for the board before the elections. Currently, all members of the managing board of the Federation are themselves Deaf, which is also the case for the presidents of all Deaf associations I have seen. Some Deaf associations employ hearing interpreters out of their own funds, often hearing children of Deaf parents. The interpreters will interpret telephone conversations, assist with the drafting of documents in Turkish, accompany Deaf people on important appointments, and attend hearing visitors. Meetings among members of Deaf associations are conducted in sign language. With all these factors taken into account, the Deaf community has achieved a considerable degree of selfgovernance.

The Deaf community in Turkey meets regularly at the local, regional and national level. The most developed and active infrastructure seems to be at the level of sports organizations, with many tournaments organized at all levels. On the other hand, cultural activities are much less developed, with sign language theater and forms of sign language 'literature' rather rare or virtually unknown. Social clubs are sometimes dominated by men, with only a day or two open to women and families, but in the modern metropolitan areas, often both men and women participate equally in social activities. Apart 
from particular activities, the Deaf clubs are mostly used for socializing and for signed communication, in which, as in other countries, all members participate enthusiastically. The national television channel TRT2 provides a regular signed news program as well as a bi-weekly feature program called 'İki elin sesi' (Voice of two hands).

The Deaf education system, on the other hand, has excluded the use of sign language in the classroom since 1953. Therefore, there is generally very little interaction between Deaf schools and the adult Deaf community. No Deaf people are employed as teachers or teacher aides in Deaf schools, and, since the educational system is centralized and there are no private schools, all schools have to comply with the current educational policies. However, the Turkish government took a number of important steps in 2001 that may pave the way for a future introduction of sign language into the Deaf education system, and there is an ongoing debate about the significance of sign language for Deaf education. Schools for the Deaf range from the primary level (ilkokul, 'first school') to secondary school (ortaokul, 'middle school'), and college (lise, after the French term). The higher levels of schooling were introduced successively over time, so that older Deaf people generally only have a primary school qualification, possibly with some vocational training afterwards. Some of these, particularly the colleges that serve a wide geographical area, such as the one in Kayseri, are boarding schools. Some institutions, such as the college in Adana, are integrational', with both Deaf and hearing students. While primary and secondary schools are more widespread, colleges are only available in major cities. There are about a dozen colleges for the Deaf all over Turkey, most of them coeducational. There is also a single tertiary educational institution for Deaf college graduates at Anadolu University in Eskişehir which provides vocational training in a number of subject areas. Many Deaf people with a higher level of education have switched between Deaf and mainstream schools during their educational careers. A Deaf informant in his mid-20's describes his educational experiences in the following way:

In primary school the teachers were good. They were helping and teaching us very well. Everything was good. Then secondly, in secondary school, all deaf (children) were studying (together). The teachers didn't give us any education, they were lazy. Everyone was just sitting around (uselessly). We became intellectually dull. No-one (of the students) could read and write. All the deaf (students) were genuinely (trying), but the teachers were bad. It was no good. They were teaching us nothing at school. Then after finishing (secondary school), in college deaf and hearing (students) were mixed. That was very difficult. I would try to hear the teacher, try to write and listen to the talking, but I could not hear anything. It would have been really necessary (to use) sign language. It would have been necessary to understand what was being taught to us. (But) there was nothing.

Most Deaf people express similar frustrations with their education, in particular with regard to the lack of effective communication between teachers and students in the 
classroom. However, it is interesting to note that earlier private schools for the Deaf did sometimes follow a bilingual approach, using both Turkish and sign language. Oral-only education was imported from Britain in 1953. Before that time, bilingual educational practices have been reported by informants for an early school for the Deaf in Izmir, and another important early school in Istanbul, referring to the period around the 1940's and 1950's. Possibly, the current TID fingerspelling system, which represents the Latin-based letters of modern Turkish, but is very different from all European fingerspelling systems (see Appendix), might have evolved in this kind of bilingual teaching situation. Although earlier schools for the Deaf are known to have existed well before the foundation of the Republic of Turkey, in particular in Istanbul, information about teaching methodologies at earlier times has not surfaced yet. In Istanbul, the person instrumental in both the establishment of a bilingual Deaf school and the formation of the Turkish Federation of the Deaf is Suleiman Sirri Gök (born 1901), known to and revered by many Deaf people in Istanbul as the 'Father of the Deaf'. While there are conflicting reports about his hearing status - he was probably hard of hearing, but had quite good speech and could also communicate in sign language - there is no doubt that he introduced a bilingual teaching approach in his Istanbul school, using both signed and spoken language. Therefore, a number of Deaf people who are now in their 50's and older have had a bilingual education and are very fluent signers. One informant who is now in his 60's describes his experiences at the Deaf school during this time:

The teachers at school didn't say that (talking with) the hands was forbidden. We did (practice) lipreading spoken sentences. They would show us things, like a paper or a box, and then (show) both the sign and the mouth movements of the spoken word. Then we would practice the spoken words without signing, keeping our hands behind our backs. If we didn't understand the lip movements, (the teachers) would always show the sign and the spoken word together in corresponding pairs, and that was very good. Previously, the teachers didn't do the wrong (thing) to cut off the sign language. Signing and speaking was always together, and went on together in this way all along. The same should be done now. Both signing and speaking has to be allowed.

While crucial links about Deaf history for the period around the end of the Ottoman Empire and the beginning of Deaf education are still missing, there is some evidence for the existence of a sign language used at the Ottoman court from as early as 1500 onwards (Miles 2000). The evidence gathered so far suggests that a fully complex sign language may have existed for several centuries at the Ottoman court and was indeed regarded as a status language and used by both Deaf servants and hearing members of the court. Due to the lack of information covering the critical period of transition, it is not possible at this stage to argue either in favour of or against a continuity linking the old Ottoman sign language to modern TID. The modern sign language does not seem to have descended from a European sign language because it is quite unlike any 
known European sign language in many domains of both lexicon and grammar. In particular, there are no suggestive commonalities between TID and LSF (French Sign Language), although France was the European nation most closely associated with the Ottomans and would thus be the most likely candidate for linguistic influence. If a link between the old Ottoman sign language and the modern sign language could be established, this would make TID the oldest documented sign language in the world, older than any documented European sign language. While this issue cannot be resolved at this stage, it is of great potential importance to the identity of the presentday Deaf community. The question of a possible relationship between Ottoman signing and modern TID will be explored in more detail in Section 3.2.

To explore issues of Deaf identity as well as issues of sociolinguistic interest, it is instructive to have a look at the way Deaf people talk about their language and community. As in other sign languages (cf. Kyle et al. 1985:319 for British Sign Language, Zeshan 2000b: 21 for Indo-Pakistani Sign Language), there is no word for 'language' in TID. Rather, the sign language is referred to as İ̧̧ARET 'sign' (see Figure 1) or TÜRK/TÜRKIYE İŞARET 'Turkish/Turkey sign'. The term used here, Türk İşaret Dili (TID), is more or less a translation of the sign language term and is also the term that signers with a good knowledge of Turkish offer as a translation of the sign language term. Terms for spoken languages are systematically ambiguous between the name for the country, the name for the language, and the name for the people, e.g. almanya/ALmanca 'Germany, German (language or people)'. Although the territory of Turkey includes people who do not ethnically identify as 'Turks', and this is an issue of continuing political debate in Turkey, it seems that deafness supersedes ethnicity as a marker of identity, that is, people primarily identify as 'Deaf' rather than 'Turkish Deaf', 'Kurdish Deaf', and so on. Whereas the relationships between Deaf and hearing people are always a matter of concern in any Deaf association, ethnicity does not seem to be a matter of great concern in the Deaf community.

With regard to hearing status, TID signers frequently use distinct terms for three

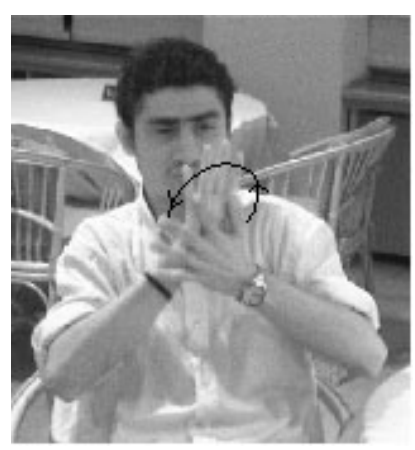

Figure 1. İşARET 'sign' 
categories of people: 'Deaf', 'speaking', and 'half', that is, hard of hearing. Interestingly, it is rather rare to refer to people as 'hearing'. The term for hard of hearing people is particularly revealing, consisting of the sign for 'half' and the corresponding mouthing yarm, but with the place of articulation shifted so that the hand draws a vertical line across the middle of the face. The sign 'Deaf' is used in combination with two different mouthings that both consist of two Turkish words coordinated with the double contact of the index finger at the corner of the mouth and then at the ear. The first mouthing, sağır dilsiz 'deaf dumb' (lit. 'deaf without-tongue/language') is the older, more traditional term, whereas younger people, under the influence of more recent political correctness, often use the term işitme engelli 'hearing impaired' instead. This is also the way hearing professionals in the field refer to deaf people.

The Deaf community in Turkey, particularly in the metropolitan areas, has had some exposure to the issues that are presently discussed in Deaf communities in Western countries, such as the redefinition of deafness as involving a linguistic and cultural minority. A considerable number of Deaf people have travelled abroad, mostly to European countries for Deaf sports competitions or to visit relatives. There is also a small but steady flow of Deaf European tourists coming into Turkey. However, contact with Deaf communities in other countries is still rather limited and a matter of chance rather than planning, and has not so far translated into official statements or policies. The use of the internet in general and e-mail in particular is also very limited, whereas mobile telephones with SMS services are hugely popular in the Turkish Deaf community. This is despite the rather poor competence in written Turkish that presents a problem for the majority of Deaf people.

Linguistic research on Türk İşaret Dili is only just beginning. Apart from a first sign language dictionary produced in Ankara in 1993, there is very little published material about the language. Academic research is even more scarce. Koç University in Istanbul is involved in a project under the direction of Dr. Aslı Özyürek and has produced the first web resource on TID (Özyürek \& İlkbaşaran 2003).

This article is based on fieldwork that I conducted in western and central Turkey between September 2001 and January 2002. The data mainly consist of videotaped spontaneous conversations in TID, augmented by some linguistic elicitation with a trained informant, a television program, and elicited lists of grammatically important signs. Of the 10 hours of conversational data, about one hour has been transcribed and coded in the sign language analysis program SignStream ${ }^{\mathrm{TM}}$. This constitutes the core of the data from five highly fluent informants ranging in age from their 20's to their 40's. The untranscribed data has been used to corroborate evidence from the smaller core corpus and includes both male and female informants, with the youngest in their teens and the oldest in their 60's. Informants were filmed in Deaf clubs in Istanbul, Ankara, Izmit and Eskişehir. Students from the vocational training center at Anadolu University contributed data from Kayseri in central Turkey and from Adana on the southern coast. 
Nine of the more than 20 subjects whose sign language data are used for the research project are native signers, with either Deaf parents or older Deaf siblings. The main informant who was involved in my fieldwork and who received training in sign language research methodology is a third-generation hearing signer with Deaf parents and Deaf grandparents.

\section{Aspects of TID grammar}

This article presents some aspects of the grammar of Türk İşaret Dili that are particularly interesting from a typological point of view. This mainly means that they have not been widely described for other sign languages and have the potential of broadening our understanding of grammatical structures that occur in geographically and genetically diverse sign languages. The exploration of the range of grammatical variation in sign languages is one of the major goals of sign language typology (cf. Zeshan forthcoming). In the five remaining sections, I discuss the following aspects of TID grammar: A putative movement derivation for completive aspect, types of nonmanual negation, negative cliticization, an honorific classifier, and a question particle.

\subsection{Completive aspect movement derivation}

Crosslinguistically, by far the most common way of marking completive aspect in sign languages, indicating the completedness of an action, is by way of a particle, that is, an independent sign. In many sign languages, a sign originally meaning 'to finish' has turned into a completive aspect marker. Sometimes the original predicate meaning is still present, so that the sign FINISH has become multifunctional, being used both as a regular predicate and as an aspect marker. Indo-Pakistani Sign Language (IPSL) has a completive aspect particle that is different from and independent of two signs for FINISH and is used as an aspect marker only (Zeshan 2000a:62ff). The category of completive aspect is very common across sign languages, whereas grammatical tense is quite rare. Tense is most commonly expressed at the discourse level in the form of lexical time signs such as BEFORE, FUTURE, and so on.

The TID construction discussed here is not unusual with respect to the category of completedness it expresses, but rather with respect to the way in which the category is encoded. Completed action can apparently be signalled in TID through the use of a particular movement pattern that is overlaid over a predicate sign. Again, the use of movement patterns to express aspect, and also aktionsart, is nothing unusual in sign languages. All sign languages described so far use patterns such as repeated movement or movement distributed over the sign space to express meanings such as 'do something repeatedly', 'do something in various places', and so on (Baker-Shenk \& Cokely 
1996: 401ff for ASL, Zeshan 2000a: 66ff for IPSL, Sutton-Spence \& Woll 1999: 118ff for BSL). However, a movement pattern indicating completed aspect has, to the best of my knowledge, not been reported for any sign language before.

TID does have two signs тAмAм 'done, complete, ready' and BITTI 'finish(ed)' (see Figures 2 and 3), which can be used to indicate completed action both at the sentence level (1), and at the discourse level, occurring at the end of a paragraph (2) or at the end of a text (3). Another sign olmak 'be, become' seems to have a related, resultative function ('have become'), and thus mostly occurs with stative predicates (cf. example $15 \mathrm{f}$ in Section 2.3). The function of these three signs is not sufficiently clear yet. However, it does seem that for the most part, manual signs indicating completedness are limited to contexts that are compatible with a more literal reading of 'finishing, completing.

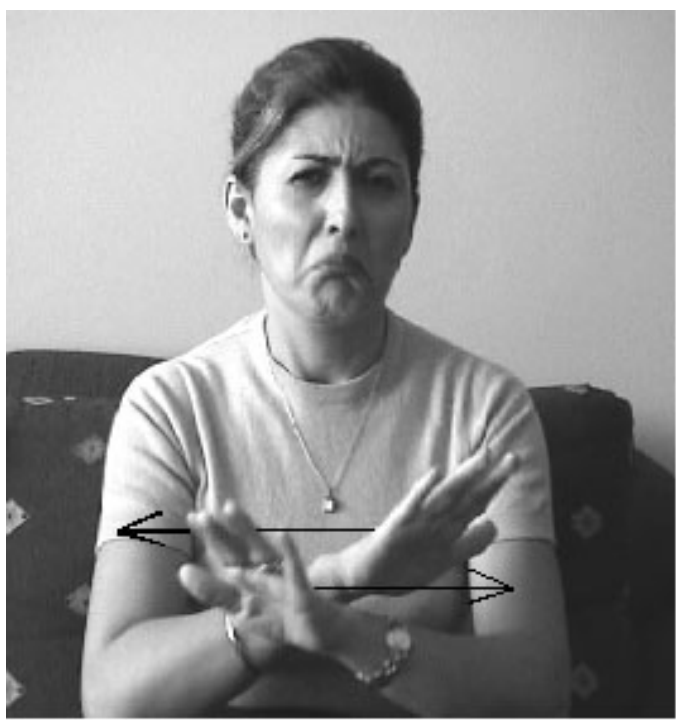

Figure 2. тАмАм 'done, complete, ready'

(1) BEN OKUL TAMAM

$\mathrm{IX}_{1}$ school done

'I have finished school.'

(2) BEN O $_{\text {sol }}$ İşARET TELEVIZYON O $\mathrm{O}_{\text {sol }}{ }_{1} \mathrm{HABER}_{\text {sağg }}$-tekrar BítTí $\mathrm{IX}_{1} \mathrm{IX}_{\text {left }}$ sign television $\mathrm{IX}_{\text {left } 1}$ message $_{\text {right }}$-iterative finish 'I kept telling them (the deaf) in signs what was happening on TV, that's one thing.'

(3) SONRAKI HAFTA TAMAM sol.yukarı UÇAK $_{\text {ön }}$ GELMEK TAMAM next week done leftup airplane $_{\text {fwd }}$ come done 'After a week, (the trip) was over and I came back home, and that's it.' 


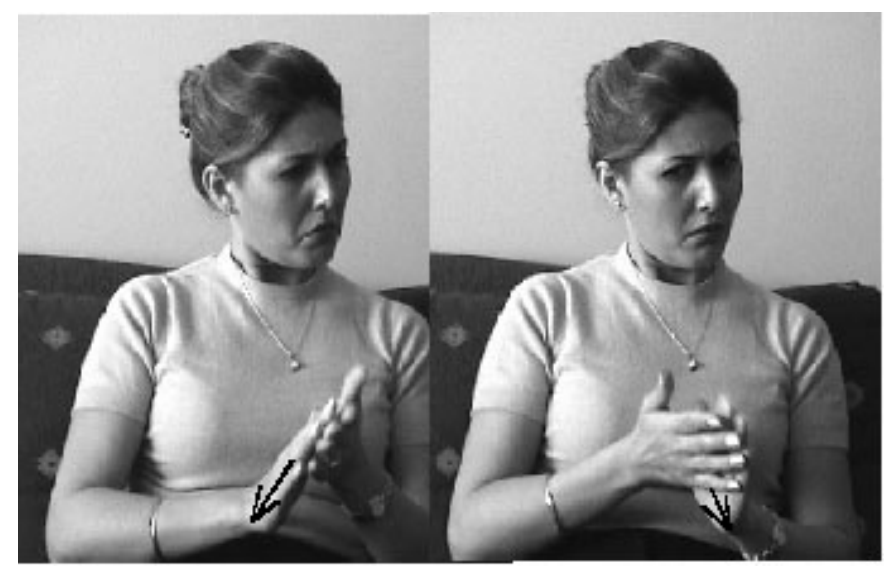

Figure 3. вїтті 'finish(ed)'

On the other hand, the putative completive movement pattern quite commonly occurs with a wide range of predicates (of both the directional and the non-directional type). ${ }^{1}$ Accordingly, the meaning of the movement pattern seems to be more abstract, conveying a general notion of completedness (4-6). Note that translations such as 'finish seeing', 'finish going', and so on, are not adequate to express the meaning of the predicates with the completive movement derivation.

(4) BAKMAK^DEĞIL BAKMAK^DEĞİL GÖRMEK-son/tam look^not look^not see-completive

' (I) couldn't see it for some time, (but finally) I saw it.'

(5) TÜRKIYE BURADA YAPMAK-son/tam

turkey here do-completive

'I have done it here in Turkey.'

(6) İsviçRe BEN GítMEK-son/tam

Switzerland $\mathrm{IX}_{1}$ go-completive

'(Then) I went to Switzerland.'

The movement pattern itself consists of a single accentuated movement, which may have a longer movement path than its noncompletive counterpart and may be accompanied by a single pronounced head nod or, alternatively, a forward movement of the whole torso. Figures 4 and 5 (videoclips 1 and 2) show the predicate GítмeK 'go' in the completive and the noncompletive form. The exact range of predicates that can

1. 'Directional' refers to the well-known grammatical process of expressing the relationship between arguments of the verb through movement between two locations in space and/or the orientation of the hand in space, as with the TID sign EĞїтім 'teach' (cf. example 13c and Figure 8 in Section 2.2). Directional signs are also known as 'agreement verbs', e.g. Padden 1990. 


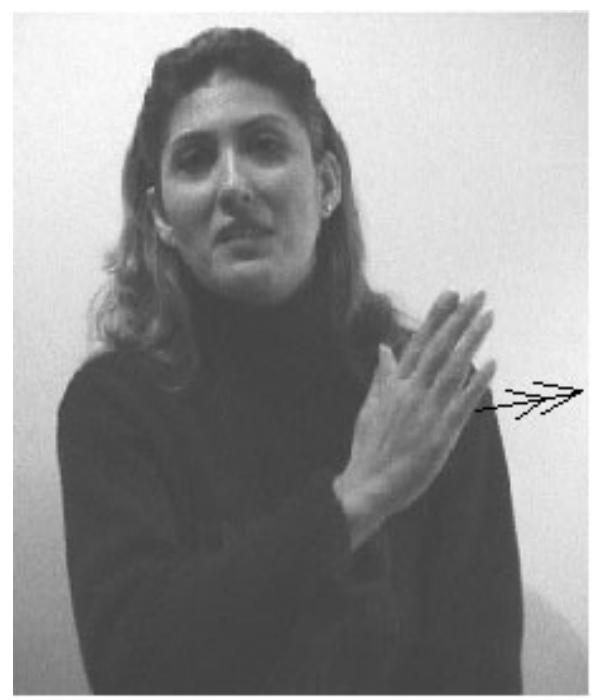

Figure 4. Noncompletive form of GİTMEK 'go'

Movie 1.

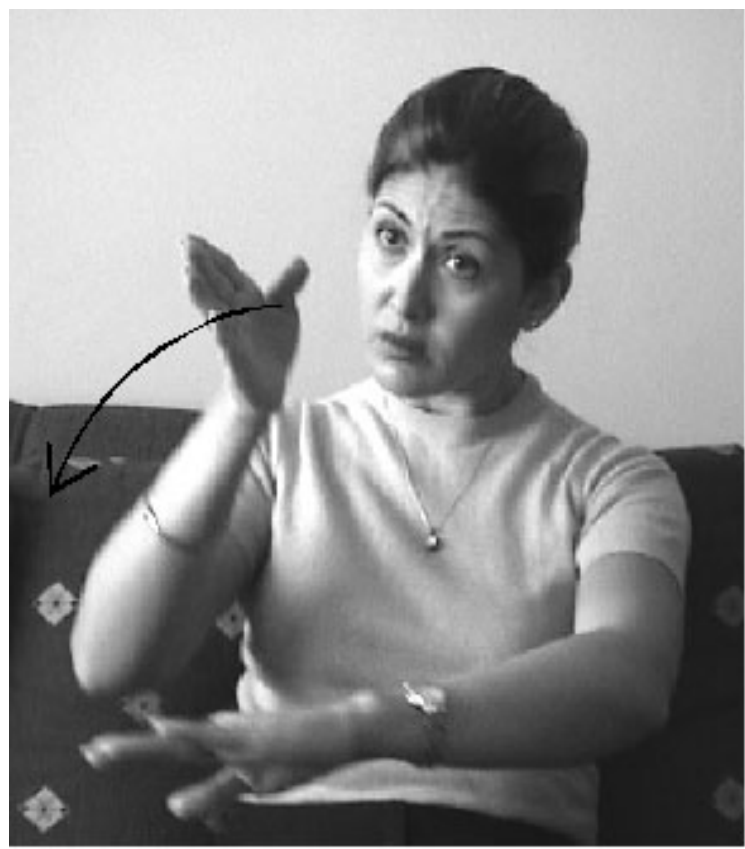

Figure 5. Completive form of GİTMEK 'go'

\section{Movie 2.}


take this derivation is to be determined yet. One factor that would seem to limit the application of the movement pattern is the fact that it cannot apply to signs that consist of a hold only and thus have no movement that could be modified in the required way. For example, whereas anlamak 'understand', a sign with the hand closing as it approaches the temple, can appear in the completive aspect form, the sign FIKIR 'think' cannot because it just consists of a hold of the index finger at the temple. The same probably applies to a number of other types of movement patterns such as finger wiggling, as in the sign HAYAL 'dream', with arms crossed at the wrists and two fingers wiggling. Examples of predicates occurring in the putative completive aspect form include gÖRMEK 'see', YAPMAK 'do' (videoclip 3), gítMeK 'go', varmak 'arrive' (videoclip 4), and ANLAMAK 'understand'.

Movie 3. YAPMAK

Movie 4. VARMAK

The exact differences between completive and noncompletive forms depend on the individual sign involved, but always include the single accentuated movement as a main component. For example, yА МмAK 'do' has a small repeated movement in its noncompletive form, but loses the repetition in the completive form. GÖRMEK 'see' has a single movement in both forms, but the movement path is longer and more tense in the completive form and goes downward as well as forward. Head and body position in the completive forms also differ markedly from the noncompletive forms. The nonmanual components are synchronized with the movement of the hand and seem to emphasize and enhance the visual effect of the movement pattern. Nonmanual components do not occur by themselves to mark completive aspect, but it is not quite clear at this stage whether they are an obligatory component of the movement derivation.

The movement pattern, with the accompanying nonmanual components, seems to have an affinity with emphatic forms of signing, so it is worthwhile asking whether the movement pattern is actually only a matter of emphasis and the interpretation as a completive aspect a matter of pragmatics rather than grammar. That is, do signers actually say something like 'I do/did see it' rather than 'I have seen it', so that the completive interpretation would be a matter of pragmatic inference based on the emphatic form rather than a genuine grammatical aspect? Wilbur \& Schick (1987) describe formational differences that occur when signs are stressed in American Sign Language, and these include some of the features of the pattern discussed here. Moreover, it has been widely reported that a head nod can have an affirmative, emphasizing function (Zeshan 2000a: 111ff for IPSL, Sutton-Spence \& Woll 1999:92f for BSL, Baker-Shenk \& Cokely 1996:155f for ASL). Some of our data also suggest, 
although this has not been investigated specifically, that a form similar to the completive aspect movement pattern is used in TID imperatives, which in turn have a natural affinity with emphasis. Therefore, the alternative interpretation of the movement pattern as emphatic cannot be ruled out at this point, and further research is necessary to determine the exact nature of the meaning change resulting from the change in movement pattern. It is also possible that one and the same form is being grammaticalized in different ways in TID.

The existence of two distinct forms of one and the same predicate as illustrated in Figures 4 and 5 is not in question and appears in many examples in the data. What needs to be confirmed is the exact function of the two forms. In the context of a contrast between an unfinished and a finished action, there may be a sense of emphasis in addition to the sense of completedness, but this could just as well arise from the discourse as a whole rather than from the movement derivation. A number of examples in the data, including example (4) above, are of this type because the target form is more easily elicited and detected in such a context. However, in other examples from signed texts there is no indication that the predicate should be interpreted as being emphasized. Examples such as (6) above have no such connotation, and the interpretation and translation of the predicate Giтмек 'go' in (6) does not involve any indication of emphasis. On the other hand, all examples found so far are compatible with a completive reading, so that we may cautiously posit this as at least one of the functions of the movement pattern in question, until further evidence becomes available. This interpretation also corresponds more closely to the Turkish rendering of these forms produced by our main informant, who consistently translated these forms into the Turkish past tense (e.g. gördüm 'I saw').

Although all examples found so far refer to the past, the movement derivation does not mark grammatical tense. TID has other means of marking tense at the discourse level by using time lexemes in the same way as other sign languages do. The data corpus contains many utterances that refer to the past tense, but are not in the putative completive aspect form. This form is only used when the signer wants to stress that an action is complete. In Zeshan (2000a:64), I give examples of the IPSL completive aspect particle being used in present tense and future tense contexts, and similar examples may well be found for the TID completive movement pattern as well. In the light of the various kinds of evidence, I conclude that at least one of the main functions of the movement pattern discussed here is likely to express completive aspect, a category that is not usually expressed in this way in other sign languages.

\subsection{Types of nonmanual negation}

Sign languages typically combine both manual elements (that is, negator signs) and nonmanual elements (that is, head movements and facial expressions) for negation. 
Although the grammatical constraints on the use of manual and nonmanual negation can be very different across sign languages (see Zeshan in press $c$, for a typological survey), the principle of encoding negation in these two ways holds for all known sign languages. This is a characteristic of sign languages that is quite different from spoken languages. Since nonmanual signals could be equated with intonation in spoken languages (Sandler 1999a), both being suprasegmental and fulfilling a similar range of functions, the equivalent of this kind of negative marking in spoken languages would involve a negator combined with a special negative intonation contour. We do indeed find this kind of structure in some spoken languages, for example in the Kuot language of New Ireland (Lindström 2002), but it seems to be a rather rare phenomenon in spoken languages. Moreover, many sign languages allow for the possibility of expressing negation entirely by nonmanuals under various circumstances, and sometimes this is even the most common way of expressing negation. In spoken languages, on the other hand, there is no documented case to the best of my knowledge where negation would regularly be expressed by a specific intonation contour only. The nonmanual expression of negation thus involves major differences between signed and spoken languages and has, not without reason, attracted considerable attention in the sign language literature. This section will deal with aspects of nonmanual negation in TID.

The most common nonmanual signal used for negation in sign languages is a sideto-side headshake. So far this negative headshake has been identified in all documented sign languages, although its grammatical status varies quite a lot across sign languages ( $\mathrm{cf}$. Zeshan in press c). In addition to the negative headshake, there is a second, quite different head movement that is used for marking negation in some sign languages only. This head movement consists of the head being tilted backward, usually accompanied by raised eyebrows (see Figure 6). It is apparently an areal feature of sign languages in the Eastern Mediterranean and possibly some adjoining Arabic-speaking countries and thus occurs in sign languages in Greece, Turkey and Lebanon. Antzakas (forthcoming) describes the use of this head movement in Greek Sign Language and notes that the same head movement is used among the hearing population in Greece and elsewhere. While there definitely is a connection between the head gesture used among the hearing population and the nonmanual signal used in sign languages in the same region, the overlap is not complete. The negative head tilt is used among hearing people in parts of Italy (Morris 1979) and in Israel, but it is not found in Italian Sign Language and in Israeli Sign Language. Moreover, the head gesture when used by hearing people in the region is often accompanied by a dental click sound, which may be absent in the sign languages. In Turkey, both hearing people and Deaf signers use the negative head tilt as well as the eyebrow raise, but no instance of a co-occurring dental click has been observed in the TID data.

TID uses both the side-to-side headshake and the backward head tilt. The details of co-occurrence restrictions with manually produced signs in general and manual 


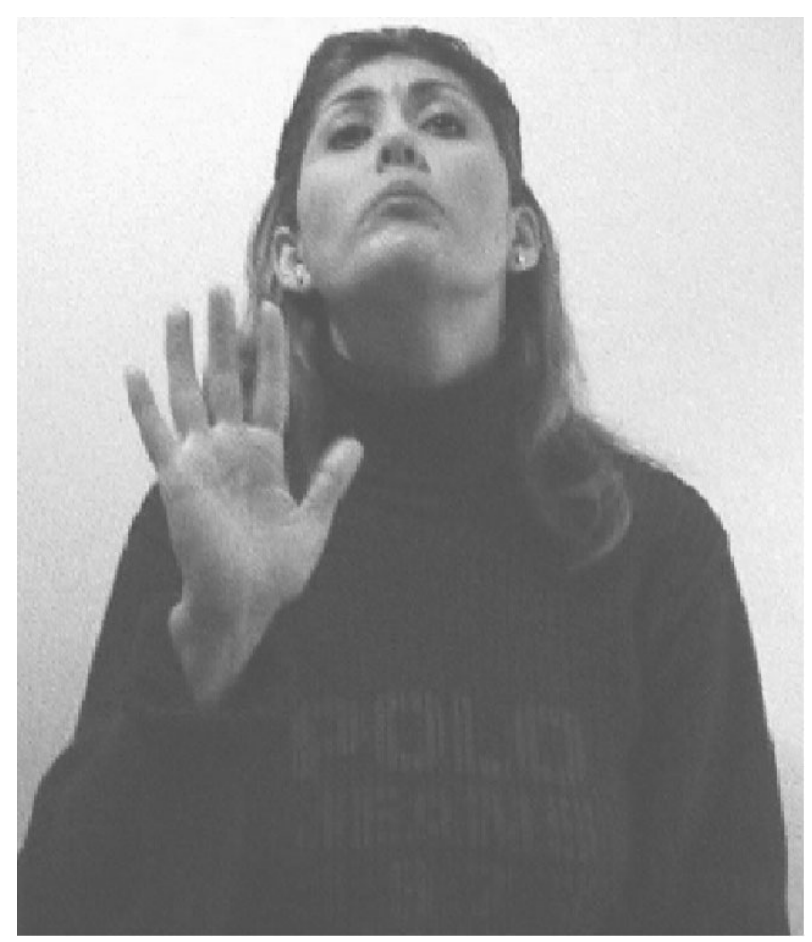

Figure 6. Backwards head tilt for negation

negators in particular have not been investigated sufficiently yet. However, some tendencies will be noted here that emerge from the available data.

The choice of negative head movement seems to correlate to some extent with the choice of the manual negator sign. With negator signs that have an upward or backward movement, the backward head tilt will be used, while the negative headshake will be used with negator signs that have a sideways or side-to-side movement. In particular, the negatives DEĞíl 'not' and OLMAZ 'cannot' tend to co-occur with the backward head tilt, while the negatives HAYIR 'no' and yo 'no-no' co-occur with the negative headshake (Figure 7 ). ${ }^{2}$ Co-occurrence patterns with negatives which have neither of these two movement patterns or have variants with different movement patterns, such as yoK 'not exist' and Hiç 'none', are yet to be investigated. Examples 7-10 illustrate the co-occurrence preferences. Similar patterns have also been noted by Antzakas (forthcoming) with respect to Greek Sign Language. However, the cooccurrence patterns in TID are clearly preferences rather than strict rules, since

2. Possibly, a reduced version of the side-to-side headshake is sometimes used in the form of a single sideways turn of the head. This has not been investigated in detail. 


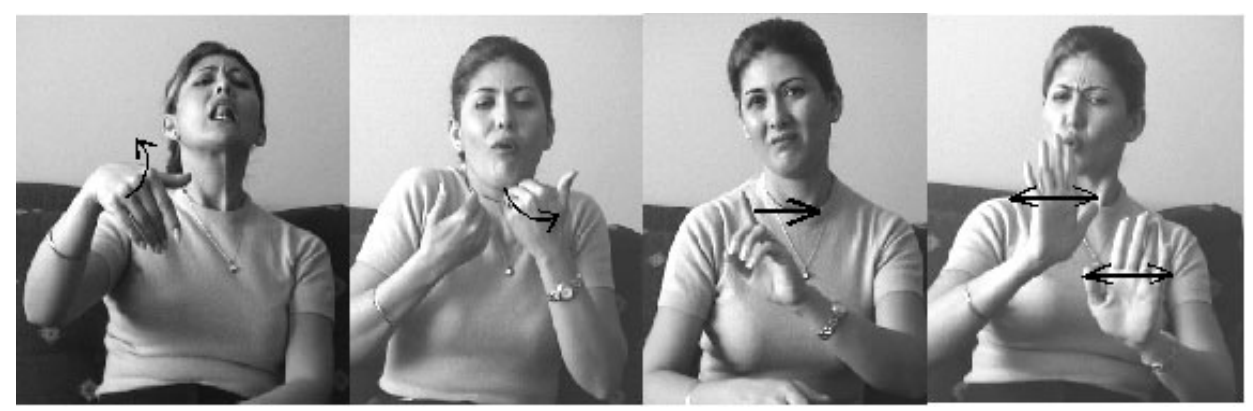

Figure 7. Negators DEĞil 'not', olMAZ 'cannot', HAYIR 'no', yo 'no-no'

counterexamples can be found for all negative items (see example 14a in Section 2.3 for an instance of DEĞiL accompanied by a headshake). More research is needed to determine the exact nature of the co-occurrence constraints involved.

(7) head back

OLMAZ

cannot

'That's impossible. / No way.'

(8)

PARA $\frac{\text { head back }}{\text { KENDİ DEĞİL }}$

moneyself not

'There is no money involved for ourselves.'

(9)

$\underline{\text { headshake }}$

BEN EŞ/EVLENMEK KAVGA YO

$\mathrm{IX}_{1}$ spouse/marry fight no-no

'Oh no, I don't fight with my wife.'

ÖĞRETMEN ${ }_{1}$ EĞİTiM $_{\text {ön }} \frac{\text { headshake }}{(2 \mathrm{el}) \text { HAYIR, TEMBEL-tekrar }}$

teacher ${ }_{1}$ education $_{\text {fwd }}(2 \mathrm{~h})$ no, lazy-iterative

'The teachers didn't give any education, they were always lazy.'

In addition to co-occurring with a manual negator sign, the negative head tilt may also occur all by itself, as in this example (videoclip 5):

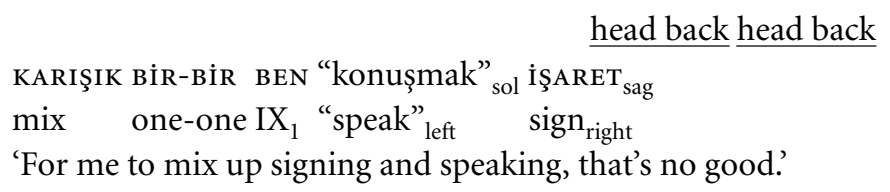

Movie 5. 
Scope regularities have not been studied in detail for either of the two head movements. Moreover, it is not clear to what extent either head movement can by itself negate a predicate without a manual negator sign being present in the same clause. With respect to the backward head tilt that particularly concerns us here as the more unusual type of nonmanual negation, it seems clear that its scope would be more restricted than the scope of the side-to-side headshake simply due to the nature of the movement itself. Whereas a side-to-side headshake can go on for as long as the signer decides, a backward head tilt, being only a single movement, does not easily spread over more than one sign, so it usually appears on the negator sign only. However, in one particular structural environment the backward head tilt does regularly spread over two signs. This happens when the negative DEĞiL cliticizes to the preceding predicate (see Section 2.3 on negative cliticization). In this case, often the predicate and the negative clitic both fall under the scope of the backward head tilt, for example:

$$
\begin{aligned}
& \frac{\text { head back }}{n} \\
& \text { BEN OKUL } \\
& \text { BX }_{1} \text { school know }{ }^{\wedge} \text { DEĞí } \\
& \text { 'I haven't been to school.' }
\end{aligned}
$$

In fact, as will be explained in detail in the following section, the scope of the negative head movement in this construction is itself evidence for the status of the negator DEĞIL as a clitic in this construction.

Whereas both the negative headshake and the backward head tilt are very common in TID, a third nonmanual signal that can convey negation is rather marginal in the language, yet nevertheless very interesting. In some rather rare contexts that still need to be specified, a puff of the cheeks with subsequent release of the air trapped in the mouth has a negative meaning (Figure 8 and videoclip 6). Moreover, the signal carries its negative meaning even in the absence of a manual negator sign, that is, it is sufficient to negate a clause by itself. In the following example, it is repeated because the predicate it co-occurs with also has repeated movement.

(13) a.

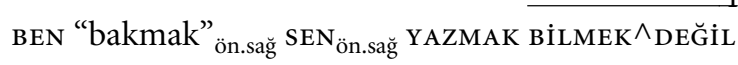

$\mathrm{IX}_{1}$ "look" fwd.right $\mathrm{IX}_{2}$ write know^not

'I looked at him (and asked), don't you know how to write?'

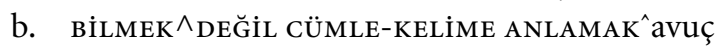
know $\wedge$ not sentence-word understand $\wedge^{\wedge}$ palm.up ${ }^{3}$

'No, I don't know, I don't understand the composition of sentences.'

3. A 'palm-up' marker occurs quite frequently in TID in various functions including negation. In this example, 'palm-up' is cliticized to the preceding predicate. This form has not however been investigated in detail. 


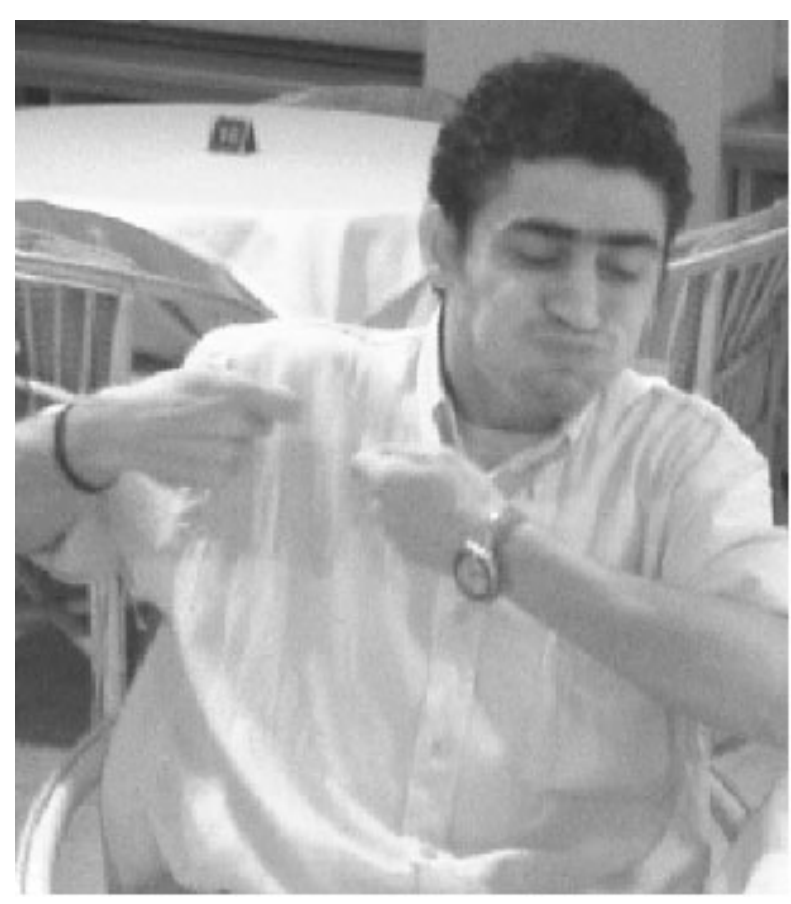

Figure 8. Puffed cheeks for negation

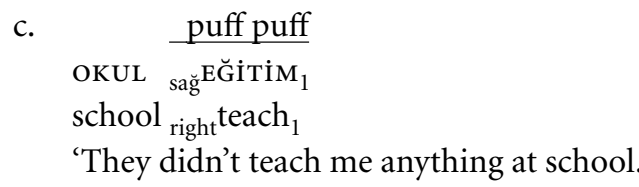

Movie 6.

The use of this nonmanual signal is interesting because, to the best of my knowledge, facial expressions have not been shown to function as negators on their own. Various facial expressions, such as frowning or pulling down the corners of the mouth, do accompany negation in many sign languages (e.g. Bergman 1995 for Swedish Sign Language, Coerts 1992 for Sign Language of the Netherlands, Berthiaume \& Rinfret 2000 for Langue des Signes Québécoise). However, it is often unclear whether they should be considered grammatical or affective facial expressions. In any case, they always occur in addition to some other manual or nonmanual marking of negation, not as the sole marker of negation as in the above example from TID. Therefore, the 'puff cheeks' negation can be considered typologically unusual for sign languages, thus broadening our understanding of the range of linguistic diversity that is possible across sign languages. 


\subsection{Negative cliticization}

On a morphological scale ranging from free forms (words) to bound forms (affixes), clitics occupy an intermediate position. They are not quite like free words anymore, but not quite like bound affixes yet. They attach themselves to another word, called the host, yet their association with their host is less close than the association between an affix and the word stem that the affix is attached to. Dixon \& Aikhenvald (2002) define clitics in terms of the relationship between phonological words and grammatical words, that is, a host-clitic combination makes up a single phonological unit, but the clitic still constitutes a separate grammatical unit of its own. Two important differences between a clitic and a free word form are that clitics cannot receive stress (which is why they are not considered phonological words by themselves) and that clitics occur in a fixed position with respect to their host. Clitics are different from affixes in that they can be considered a grammatical unit of their own for syntactic purposes. As with most linguistic distinctions, the distinction between clitic and affix is sometimes fluid. Moreover, we sometimes find pairs of forms with a fuller form functioning as an independent word and a reduced form functioning as a clitic. This tendency, which can typically be observed with clitics but not with affixes, will be explained in more detail below with reference to the TID negative clitic.

Since cliticization has not been widely discussed in the sign language literature so far, I will first give a few well-known examples of clitics from spoken languages. In English, the negator not and the auxiliary have can cliticize to a host and then appear in the reduced forms n't and 've, as in is not versus isn't and we have versus we've. The forms with the clitics represent a single phonological unit, and the clitics cannot be stressed independently. However, the grammatical function of the negator and the auxiliary remains intact and unchanged. It is only the phonological form that gets reduced in cliticization. In Romance languages, pronoun clitics are widespread and can occur in clusters, such as French je t'ai vu 'I have seen you (I you-have seen)' or je te l'ai dit 'I have told you about it (I you it-have told)'. The pronoun clitics have a fixed position with respect to the inflected verb form and with respect to each other, and they cannot be stressed. In Turkish, a clitic de meaning 'also, too' follows its host, as in sen de 'you-too', and both together constitute a single phonological unit where nothing else can come in between.

For sign languages, Sandler (1999b) investigated characteristics of clitics in Israeli Sign Language. Subsequently, I presented evidence for pronoun clitics in a number of other sign languages in Zeshan (2002). Evidence for pronoun clitics in sign languages come from three different domains:

a. phonological evidence: loss of syllabicity, loss of movement, loss of specification for location;

b. syntactic evidence: clitic + host behaving as a single sign for the purpose of 
assignment of suprasegmentals (head movements, mouth patterns), clitic + host sign occurring simultaneously;

c. functional evidence: cliticization occurs with elements that function as deictics, pronouns and determiners (Zeshan 2002).

The first group of criteria refers to the fact that clitics have a reduced phonological form in comparison with free forms, so that the clitic cannot be considered a phonological word of its own (cf. English 've). Secondly, syntactic evidence demonstrates that clitic and host behave like a single sign in some respects. Finally, functional evidence depends on the observation that certain grammatical categories are particularly prone to cliticization crosslinguistically. This includes pronouns, but also negatives (cf. English $n^{\prime} t$ ). An analogous set of criteria can be applied to the negative DEĞiL 'not' in TID to show that it cliticizes to a host sign, the preceding predicate.

When the negative DEĞiL 'not' (see the first picture in Figure 7 in Section 2.2) cliticizes to a preceding predicate, several aspects of its form change. Example 14 and the accompanying videoclip show two instances of DEĞiL 'not' in combination with the predicate BİLMEK 'know', first with DEĞiL 'not' in its full form as an independent word (transcribed as BíLMeK DEĞíl 'know not') and then with DeĞí 'not' as a clitic (transcribed as BíLMEK ${ }^{\wedge}$ DEĞIIL ' $k$ now ${ }^{\wedge}$ not' $^{\prime}$ ). As noted above, it is not uncommon for clitics to have a corresponding full form, such as English not versus $n^{\prime} t$, and this is one of the reasons why DEĞiL is considered a clitic and not an affix here.

(14) a.

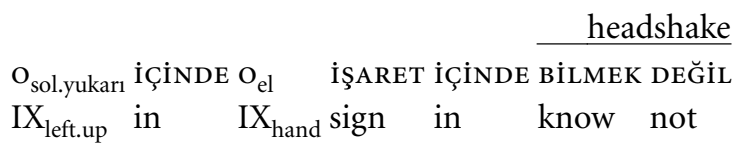

'They (the hearing people) don't know anything about sign language.'

b. headshake

$\mathrm{O}_{\text {sol }}$ DÜNYA İÇINDE BILMEK^DEĞIL

$\mathrm{IX}_{\text {left }}$ world in $\mathrm{know}^{\wedge}$ not

'They don't know what's in this world (of signing).'

c. BEN BİLMEK

$\mathrm{IX}_{1}$ know

'But I know.'

\section{Movie 7.}

The formational differences between DEĞiL 'not' as a full form and $\wedge_{\text {DEĞIL ' }} \wedge$ not' as a clitic are summarized in Table 1 . All of these differences have the effect of reducing the 'phonological content' of the clitic and/or assimilating the clitic to the host sign by carrying over formational properties from the host sign to the clitic.

In addition to these formational differences, a syntactic argument can be made about the behavior of suprasegmentals in this construction, demonstrating that, just like the 
Table 1. Formational differences between the full and the cliticized form of DEĞiL

\begin{tabular}{|c|c|}
\hline DEGiL full form & $\wedge_{\text {DEGiL cliticized form }}$ \\
\hline $\begin{array}{l}\text { movement consists of full wrist bending } \\
\text { changing orientation of the finger tips by } 180^{\circ} \\
\text { from downwards to upwards }\end{array}$ & $\begin{array}{l}\text { movement is much reduced, consisting only of } \\
\text { some wrist bending of much smaller magnitude } \\
\text { (loss of syllabicity) }\end{array}$ \\
\hline $\begin{array}{l}\text { duration of the sign is comparatively longer, } \\
\text { amounting to a full syllable }\end{array}$ & $\begin{array}{l}\text { duration of the sign is much shortened (loss of } \\
\text { syllabicity) }\end{array}$ \\
\hline $\begin{array}{l}\text { sign starts with finger tips facing downwards } \\
\text { and ends with finger tips facing upwards }\end{array}$ & $\begin{array}{l}\text { signs starts at whatever fingertip orientation the } \\
\text { preceding host sign ended with (assimilation of } \\
\text { orientation) }\end{array}$ \\
\hline $\begin{array}{l}\text { sign is articulated in neutral signing space in } \\
\text { front of the signer's torso }\end{array}$ & $\begin{array}{l}\text { sign is articulated at any location in sign space } \\
\text { depending on wherever the preceding host sign } \\
\text { ended (assimilation of location) }\end{array}$ \\
\hline $\begin{array}{l}\text { sign is two-handed, but has a one-handed } \\
\text { alternate form with the non-dominant hand } \\
\text { dropped (weak hand drop) }\end{array}$ & $\begin{array}{l}\text { sign must be two-handed following a preceding } \\
\text { two-handed host sign and must be one-handed } \\
\text { following a preceding one-handed host sign } \\
\text { (assimilation of handedness) }\end{array}$ \\
\hline
\end{tabular}

pronoun clitics mentioned above, the host-clitic combination with DeĞiL 'not' behaves like a single word unit. As was mentioned in the previous section on nonmanual negation, the negative backward head tilt commonly associated with DEĞiL 'not' and other negator signs usually appears on the negative only. However, in the case of cliticized $\wedge^{\text {DEĞiL }}$ 'not', the negative head tilt co-occurs with both the preceding predicate and the negative clitic, that is, it spreads to the whole host-clitic combination (see examples 15a and $15 \mathrm{~g}$ below). This behavior provides evidence for the fact that the two signs in the host-clitic combination do indeed form a unit that is equivalent to a single word unit. Finally, it has already been mentioned that crosslinguistically, it is not uncommon for negatives to occur as clitics, so that functional evidence also supports our argument.

In the following text, the signer uses DEĞiL 'not' repeatedly both as an independent sign and as a clitic, which makes it an ideal example for demonstrating the functional difference between the two. Note that the free form seems to be used for emphasis $(15 \mathrm{~b}, 15 \mathrm{j})$ whereas the cliticized form $(15 \mathrm{a}, 15 \mathrm{~d}, 15 \mathrm{~g})$ is the more usual way of saying 'don't know' in TID. In other texts in the data, the cliticized form of DEĞiL 'not' is much more common with 'know' than the full form. This seems natural considering the frequency of the expression. Other frequent combinations where DEĞiL 'not' usually occurs as a clitic include $\operatorname{seVMEK}^{\wedge}$ DEĞIL 'like not' (videoclip 8 ), ANLAMAK $\wedge^{\wedge}$ DEĞIL 'understand not', AYNi^ ${ }^{\wedge}$ DEĞIIL 'not same' (videoclip 9), and the

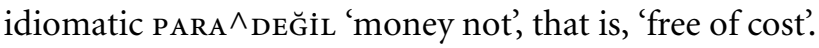


(15) a. head back

BEN KONUŞMAK BİLMEK ${ }^{\wedge}$ DEĞİL

$\mathrm{IX}_{1}$ speak $\mathrm{know}^{\wedge}$ not

'I can't speak.'

b. brow raise, head back

BEN KONUŞMAK BİLMEK DEĞİL

$\mathrm{IX}_{1}$ speak know not

'I can't speak at all.'

c. YAZMAK-KONUŞMA-tekrar

write-converse-iterative

'(So) I talk to others in writing all the time.'

d.

SEBEP KONUŞMAK BİLMEK^ ${ }^{\wedge}$ DEĞIL SEBEP

reason speak $\quad \mathrm{know}^{\wedge}$ not reason

'The reason why I cannot speak?'

e. ÖĞRETMEN $O_{\text {sağ }}$ sağ EĞITIM ${ }_{1}$ TEMBEL $O_{\text {sağ }}$

teacher IX $_{\text {right right }}$ education 1 lazy IX $_{\text {right }}$

'(It's because) the teachers didn't teach me anything.'

f. BEN APTAL OLMAK

$\mathrm{IX}_{1}$ stupid be

'(So) I became intellectually dull.'

g.

head back

BEN YAŞ-BÜYÜMEK KONUŞMAK BİLMEK^ ${ }^{\text {DEĞİIL }}$

$\mathrm{IX}_{1}$ grow-up speak $\mathrm{know}^{\wedge}$ not

'I grew up not knowing how to speak.'

h. BEN AKILLI KALMAK

$\mathrm{IX}_{1}$ intelligent stay

'I am intelligent though.'

i. İŞARET İẎ

sign good

'I can sign well.'

j. KONUŞMAK BİLMEK DEĞİL

speak know not

'(But) I don't speak at all.'

Movie 8. $\operatorname{sEVMEK}^{\wedge}$ DEĞİL 'like not'

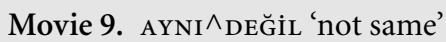


From the data gathered so far, it seems that negative cliticization is extensive in TID, ${ }^{4}$ occurring with a large number of predicates. As noted above, some combinations with the negative clitic are particularly common, and these typically involve high-frequency host signs such as 'know', 'like', 'understand', and the like. However, negative cliticization is possible with many more predicates and may even be totally productive, that is, applicable to any predicate host sign. This of course needs to be investigated in detail before such a strong claim can be made. All that can be said at this stage is that so far no particular constraints on the applicability of negative cliticization have been found. It may also be added that the existence of extensive cliticization is evidence for a history of grammaticalization and thus for at least some historical development of the language. This means that some time depth must be attributed to TID (see discussion in Section 3.2).

\subsection{Honorific classifier}

Classifiers have long been an issue of intense research and debate in sign language linguistics (Emmorey 2003 provides a good overview of current research in this domain). In this section, I would like to add some interesting data from TID which again serves to expand our notion of typological diversity across sign languages. The type of classifier construction referred to here is usually known as 'predicates of movement and location'. In these multimorphemic constructions, a handshape morpheme represents a moving entity, while the movement or location or the entity is expressed by the movement or positioning of the hand in space. For example, an upright index finger moving in a horizontal circle can represent a person walking around in a circle. The handshape in such constructions is known as a 'whole-entity classifier' because it represents the moving entity as a whole.

TID has a highly grammaticalized system of whole-entity classifiers (Zeshan 2003, for a discussion of weakly grammaticalized and highly grammaticalized classifier systems). This classifier system is typologically unusual in sign languages because it includes the grammatical category of honorifics, a category that has not been described in connection with classifiers for any other sign language. Honorific expressions serve the purpose of verbalizing status distinctions between members of society. Most commonly, they are used to convey politeness and respect for persons (and sometimes other beings) of high status. Although all languages can convey politeness and respect, only some languages, such as Japanese, have a grammatical category of honorifics. This category may manifest itself in various parts of the grammar, such as distinct honorific and nonhonorific pronoun sets or honorific affixes on the verb. In TID, the classifier

4. This also includes cliticization of 'palm-up', as in example (13b). 


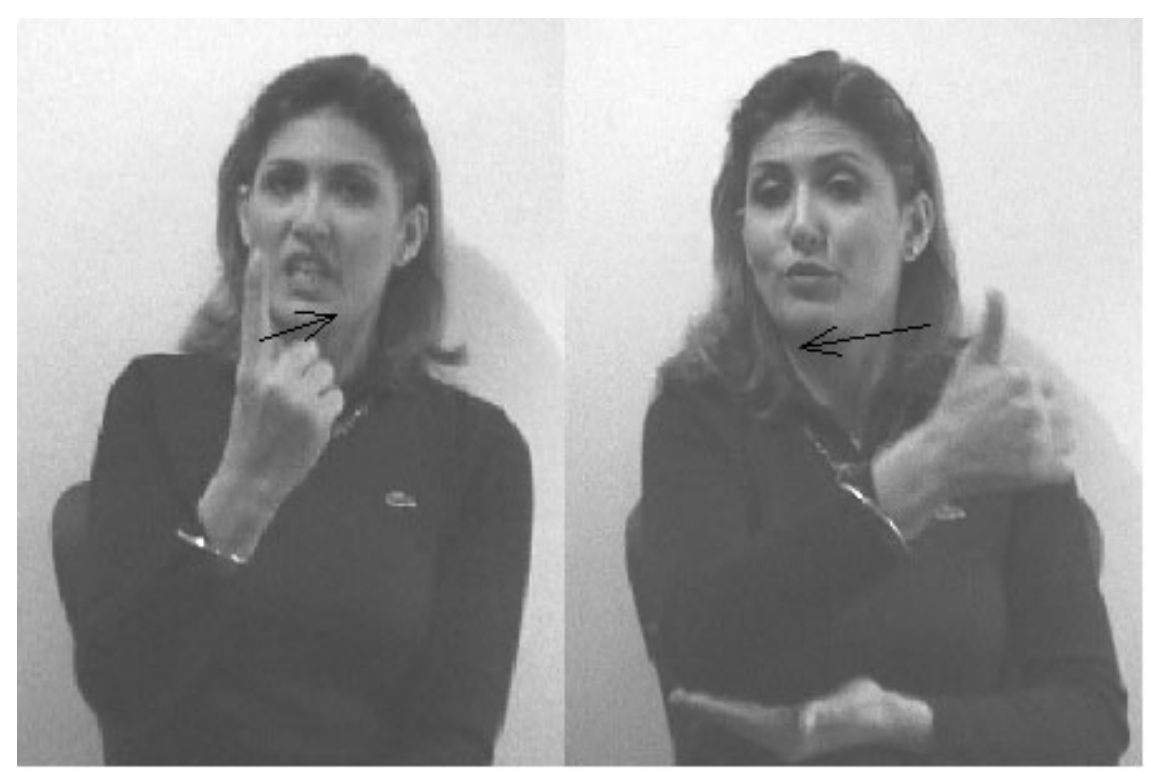

Figure 9. Nonhonorific and honorific person classifier

system includes an honorific classifier. Honorific classifiers can be found in various spoken languages. For example, in the Mayan language Jacaltec, the classifier $y a 7$ is used for 'respected humans' (Aikhenvald 2000:284). In Japanese, classifiers used with numbers or counting ('numeral classifiers') include the superordinate nin for human beings in general and the subordinate mei for human beings in an honorific sense (Aikhenvald 2000:317). In sign languages, honorific classifiers have not been described so far.

Figure 9 shows two predicates of movement and location that both mean 'a person coming. The only difference between the two is that the upright index finger refers to a person without specifying anything about that person's status, whereas the upright thumb indicates that the person is in some way important. Note that the contrast here is not 'honorific versus nonhonorific', but rather 'honorific versus neutral'. That is, the index finger does not indicate a lower status of the person referred to, but just lacks any indication of status and is thus neutral with respect to politeness or respect.

Secondly, the term 'honorific' is used in a slightly different sense here from the way it typically functions in spoken languages. Typically, honorifics are used to express respect for either the addressee or a third person, and it would thus be highly unusual or impossible in such a system to use the honorific form with respect to the first person in a form such as myself-HONORIFIC. However, the upright thumb classifier in TID can be used freely to refer to oneself as well as to other people. It thus conveys not so much a notion of politeness and respect toward other people, but rather a more 
general notion of importance or value, so that one can easily say something like 'I myself, being important.... Comparing examples (16) and (17) below, the signer refers to a third person in the first instance and to herself in the second instance (examples are transcribed in English only for convenience).

(16) a. THEN DIRECTOR CHANGE

'Then the director changed.'

b. NEW DIRECTOR CL:person.honorific center-left $_{\text {. }}$

'A new director got into this important position.'

(17) a. right hand: IX ${ }_{1}$ SMALL-AGE IX TELEVISION IX $_{1}$

left hand: TELEVISION

right hand: CL:person.honorific center-front

left hand: flat-surface:front

'I was (still) small, (but) I used to place myself in front of the television as someone important.'

b. right hand: HOUSE DEAF TEN FIVE CL:person.plural semicircle.right $_{\text {. }}$

left hand: HOUSE TEN CL:person.plural semicircle.left

'In our house, 15 deaf people would sit in a semi-circle.'

c. right hand: $\mathrm{IX}_{1}$ CL:person.honorific $\mathrm{center-front}$ SIT

left hand: flat-surface ${ }_{\text {front }}$ sit

'And I would sit down in front as someone important.'

d. IX $_{1}$ SIGN

'And I would sign (for them).'

The translations provided indicate the meaning contributed by the use of the honorific classifier. In (16b) the hand with the classifier handshape just moves from the center to the left, thus localizing the new director on the left side for the duration of this text. The complex two-handed classifier construction in (17a) and (17c) additionally incorporates a specification for a flat surface represented on the non-dominant hand. The honorific classifier can thus be used in multimorphemic constructions just as productively as any other classifier. Example (17b) includes another complex classifier construction which is used in some contexts in TID for plural reference to people. This form involves an open hand with extended fingers facing downward. The two hands describe a semicircle in (17b) to express the location of a group of people (videoclip 10).

\section{Movie 10.}

It may be added that in the construction in (17b), it also seems possible for the finger tips to be facing upward, as more commonly occurs in other sign languages and in some other TID examples. The function of the change in hand orientation for the expression of plural reference in this kind of construction has not been investigated. Note also that in the plural, the distinction between honorific and nonhonorific classifiers disappears, as the honorific classifier does not seem to have a plural form of 
its own. A full analysis of the classifier system in TID has yet to be worked out, but the existence of an honorific form as part of the paradigm of classifier handshapes will definitely turn out to be the most interesting aspect of this unusual classifier system.

\subsection{Question particle}

Question particles are used in both signed and spoken languages to indicate that an utterance is a question. Japanese, Mandarin Chinese and Turkish are examples of spoken languages with question particles. Question particles often occur in yes/noquestions only, whereas questions with question words are marked by the question word (wh-word) itself rather than by a question particle. In example (18) from Turkish, the only function of the question particle $m i$ is to indicate that the utterance is a yes/no-question.

\section{(18) SEN DE GEL- ECEK MI- SIN? \\ Pron.:2Sg also come- FUT Q- 2Sg \\ 'Will you be coming, too?'}

In Zeshan (forthcoming), I investigate question particles and their development and grammaticalization across a range of sign languages; some of the issues discussed there are also relevant to the TID question particle described in this section. Of particular interest here is the historical development of question particles in sign languages whose surrounding spoken languages also have question particles. For several sign languages, the history of question particles is documented as having arisen via influence from the surrounding spoken language. For example, a question particle mA in Taiwanese Sign Language has its origin in the Signed Mandarin system that was artificially created for educational purposes to represent spoken Mandarin 'on the hands'. The particle thus mirrors the structure of the Mandarin question particle and is still used mainly by younger signers who have been more heavily influenced by the system through their school education. In other words, use of the question particle is spreading from the artificial Signed Mandarin code into the primary Taiwanese Sign Language. Use of the question particle in Taiwanese Sign Language can thus be seen as an effect of language contact with spoken Mandarin, the contact being facilitated by the Signed Mandarin system. A question particle in Japanese Sign Language has similarly originated in Signed Japanese and is still largely limited to registers close to Signed Japanese.

In Turkish Sign Language, there is a comparable initial situation with a primary sign language used in the Deaf community as a first language and a spoken language that uses a question particle co-existing in the same region. We will first look at the form and function of the TID question particle and then explain how it is used in present-day TID and what this implies for its history.

Figure 10 shows a sign glossed mi consisting of an index finger touching the nose 


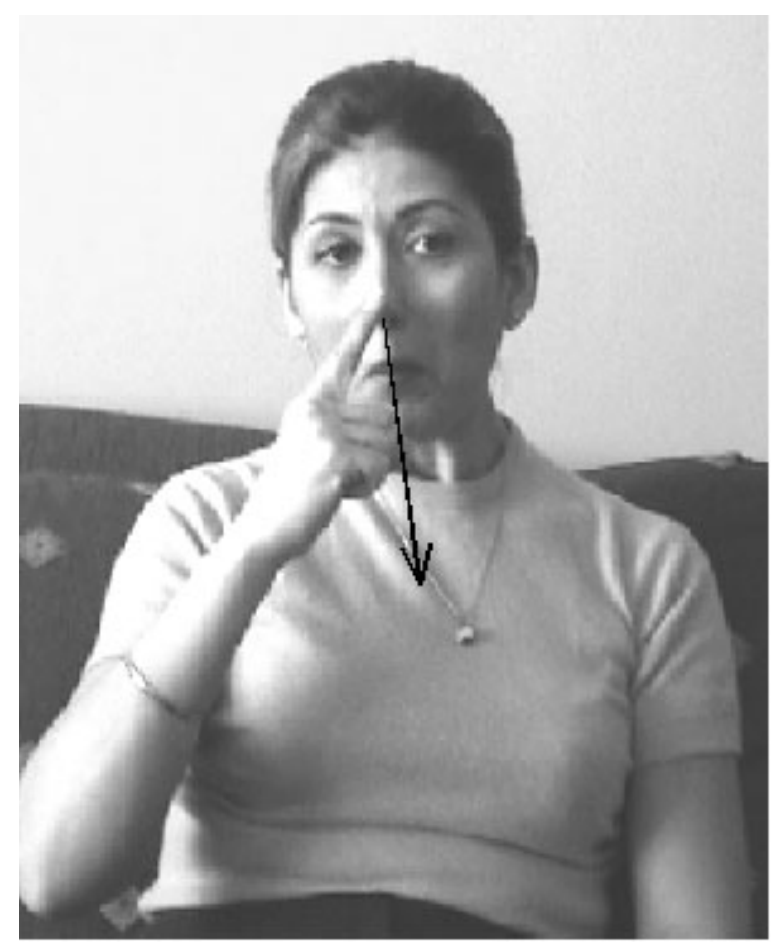

Figure 10. Question particle

and then moving downward in a straight line. A few signers optionally use this particle at the end of a yes/no-question in TID (19). At the same time, this sign is an old form of the sign NE 'what' in TID. Younger signers use a different sign for 'what' instead of the older sign. Both older and younger signers also use yet another sign for 'what' which is based on a common Turkish gesture. In its function as a question word, the sign in Figure 10 also appears in wh-questions, in particular in combination with the gesture-based sign for 'what', as in (20). The possible syntactic positions in this type of question remain to be investigated. There is evidently some degree of assimilation between the two signs at the end of (20), which results in the duration and the movement path of the old question word being much shorter compared to its use as a question particle in (19). The resulting combination is not unlike what one would expect for a sign language compound, but the exact nature of this combination has not been determined yet. q

SEN KİṠ EŞ/EVLENMEK Mİ

$\mathrm{IX}_{2}$ person spouse/marry Q-part

'Are you married?' 
(20) ÇOCUK ÇOCUKLAR KONUŞMAK ${ }_{1}$ ĔĞITIMM $_{\text {ön }} \operatorname{NE}($ eski)+NE(jest)
child children speak ${ }_{1}$ teach $_{\text {fwd }}$ what(old)+what(gesture)
'How can we teach the children to speak?'

In yes/no-questions with no question particle, the question is simply marked nonmanually by an interrogative facial expression and head position. This is the standard, usual marking of this type of question across sign languages. In questions with question words, it is the question word together with the facial expression that marks the utterance as a question. Interrogative nonmanual marking is indicated by a line labeled ' $q$ ' on top of the gloss line in the examples. However, the details of nonmanual marking of the two types of questions in TID have not been investigated. Therefore, the transcribed examples just indicate that some nonmanual marking is involved, without specifying its exact form or function. If the question particle is used, the questions are marked nonmanually also.

The sign in Figure 10 is very rare in the present-day language both in its use as a question particle and in its use as a question word 'what', to the extent that it has almost disappeared. Only a few older signers in Istanbul in their 40's and older have reported its existence. Younger signers do not use the question particle at all and may not even recognize it as a TID sign. This distribution is exactly the reverse of what has been happening in other sign languages such as Japanese and Taiwanese sign languages, where the question particles are being used more by younger signers. While question particles seem to be entering the primary sign languages in these cases, in TID the question particle is evidently disappearing. In both situations the surrounding spoken languages do have question particles, but the historical development is moving into opposite directions.

Interestingly, both developments can be explained in one and the same framework, that is, in relationship to contact with the surrounding spoken language. The language contact situation that has led to the development of question particles in the Eastern Asian sign languages has been explained above. For the situation in Turkey, a different scenario will explain the pattern we find today. In the initial section of this article, it was mentioned that a number of early schools for the Deaf in Turkey did follow a bilingual educational approach, however informally, that included the use of sign language in the classroom. Although a formal Signed Turkish comparable to Signed English or Signed Japanese was not in use, nor was there any principled or organized attempt to create such a sign system, it can be safely assumed that the language situation in the classroom at that time involved quite intensive language contact. The members of the deaf community who still know the sign mi come from the same generation of people who were educated in these bilingual settings, that is, people now in their 50's and older, as well as people who are slightly younger. 
This distribution leads us to hypothesize that the question particle probably arose out of a bilingual educational setting in analogy with spoken Turkish, maybe only in a single school, since there are other signers from the same generation who have never seen or used this sign. Although similarities of this kind were not codified in the form of a 'Signed Turkish' system, it is quite possible that a question particle would have come up spontaneously in an effort to represent an important structural element from spoken Turkish and to sign in a way more closely resembling spoken Turkish, maybe even as a distinct 'classroom register'.

An unrelated argument in favor of this hypothesis comes from considering the form of the question particle. The pointing to the nose may be related both to the initial nasal /n/ in many Turkish question words (e.g. ne 'what', nasil 'how', nerede 'where') and to the initial nasal $/ \mathrm{m} /$ in the Turkish question particle $m i$. This is indeed the argument that one informant offered by way of explanation. The development from a sign meaning 'what' or from a general interrogative to a question particle is a typical grammaticalization pathway (Zeshan forthcoming). In the case of TID, iconic reference to the nasal quality of both Turkish question words and the Turkish question particle may have facilitated this development in a bilingual situation. Subsequently, when oral-only education was established, an important pathway of language contact between spoken Turkish and TID in the classroom was cut off, since TID was banned from the classroom and only used informally among the students themselves. This would then have led to the loss of the question particle because the motivation for its use did not exist any more. Hence younger signers below the age of 40 do not use any question particle in TID.

\section{Conclusion}

\subsection{TID: Typological significance of the data}

The aspects of TID grammar presented here are interesting for their own sake, as TID needs to be described and documented in order to gain legitimacy and recognition in society in general and in Deaf education in particular. Subsequently, educational materials in and about sign language in Turkey can be produced on the basis of the initial linguistic analysis. Without a basis of sound descriptive data, applied research cannot take place.

However, the results of this initial exploration into TID structure is also significant for sign language linguistics as a whole, and in particular for sign language typology, the crosslinguistic study of sign languages. The aspects of TID grammar discussed in this article can broaden our understanding of the range of typological variation across sign languages. The experience is that the more we look, especially with respect to sign 
languages that have not been documented before, the more new insights we gain into possible variation across sign languages. There is always more in language than meets the eye, and this holds true for sign languages as well.

With respect to the TID data, the range of documented linguistic variation across sign languages is extended in several ways. In the case of the putative completive aspect movement derivation, we have a well-known morphological mechanism (modification of the movement pattern of a sign) applied to a new grammatical category (completive aspect). With the honorific classifier, we have hit upon a so-far undocumented grammatical category distinction within a known construction type (multimorphemic classifier constructions). The various types of nonmanual negation provide evidence for a novel way of expressing negation through a facial expression only, as well as insights into an interesting feature of areal typology with respect to the backward head tilt for negation. Finally, the development of extensive negative cliticization and the decline of the question particle are of interest from the point of view of historical development and grammaticalization processes in sign languages.

\subsection{TID: The history of a language}

The issue of historical development becomes particularly interesting in connection with the information about the sign language used in Ottoman Turkey as early as 500 years ago, as mentioned in Section 1. On the basis of the current evidence, it would be premature to draw any conclusions about a possible connection between the historical sign language and current TID, and thus about the age of TID as a language. Evidence drawn from linguistic structures such as extensive cliticization is only one point to investigate. Aronoff, Meir and Sandler (2000) note that the reason why sign languages have comparatively little sequential, affixal morphology may be that sign languages are young languages and arise under situations that are similar to pidgins and creoles. Since the grammaticalization process takes time, many sign languages may simply not be old enough to have undergone a development toward sequential affixing. However, we should also note that this is a very general observation and that there is currently no way of establishing what amount of sequential morphological complexity would correlate with how much time depth, nor is it likely that such a measure will be found in the future. It would seem more promising to examine the relationship between the old Ottoman sign language and modern TID more directly, by examining some of the following questions:

a. What happened to the last generation of Deaf servants at the court before the Ottoman empire broke up? Did any of them have contact with the beginnings of Deaf education, which was taking place around the same time? As we know from other documented cases in the history of sign languages, such as French Sign Language in the United States via Laurent Clerc or Swedish Sign Language in Finland via Carl Oscar Malm, it does not take many people for a noticeable impact 
on a sign language to take place. So even a single fluent Ottoman signer being involved in a single early school for the Deaf could have meant that at least some linguistic continuity would have been carried over to modern times. Obviously, the last generation of Deaf servants at the Ottoman court did not just die or disappear with the end of the Empire. Finding out what exactly happened to them, and in fact finding out much more about the lives and language of earlier Deaf courtiers, is an important part of Deaf history in Turkey even if it does not directly lead to conclusive evidence about the status and age of current TID.

b. Can any particular signs (for example, place names or signs referring to cultural practices) be traced back to Ottoman times? If a larger number of current TID sign are now perceived as arbitrary, but can be shown to have iconic content in relationship to earlier times, this would indicate that the signs are at least as old as the iconic basis they refer to. For example, it is well known the German Sign Language Sign for 'Germany' (upright index finger held at the forehead) is now essentially arbitrary, but was originally iconic, referring to a time when German uniforms with a spiked helmet were common. Similarly, a TID sign for iftar (the time of the day when the fast ends in the evening during the Muslim month of Ramadan) iconically refers to the firing of cannons that was common in earlier times to announce iftar, but is now no longer common practice. A substantial number of signs that could be traced back to Ottoman times in this way could provide some direct evidence for the age of TID. However, a substantial number would be necessary in order to compensate for possible mis-explanations or possibly flawed folk etymologies.

c. In the ideal case, it may be possible to find out more about the old Ottoman sign language itself from historical records. That is, in addition to reports stating that Deaf people were present at court and were using a sign language for such-andsuch purposes, people may also have recorded what individual signs looked like. Although this may not be very likely, and even if such records were to be found, they may not be easy to interpret, it would be the most direct evidence of a linguistic continuity over the centuries. For example, probably the earliest record of Indian Sign Language (ISL) signs is Banerjee (1928), with signs from the Bengal province. Out of 84 signs described by Banerjee, $53 \%$ are the same (40\%) or partly the same (13\%) as currently existing ISL signs, although there appears to have been a shift in meaning in some cases. Twenty-nine percent of the signs are not similar to current ISL signs. Particularly noticeable from the point of view of research methodology and data evaluation is the fact that a substantial number of signs (18\%) are not interpretable because the written descriptions given for these signs are inadequate. So evidence such as this is, again, only a very small piece in a large puzzle, and there are all kinds of reservations about how such numbers are to be interpreted. However, in the case of Ottoman signing, with its importance 
and status in the environment of a highly developed culture, the chances of getting at least some picture of the old sign language from historical sources are worth a closer investigation.

Putting together a puzzle from all kinds of evidence, both linguistic and historical, to trace back the history of sign language in Turkey is obviously of great relevance to the present-day Deaf community in terms of their identity and historical perspective. It is to be hoped that the linguistic data presented here will one day fit into a broader picture to the benefit of the Turkish Deaf community.

\section{Acknowledgments}

I am deeply grateful to my Deaf informants in Turkey, Ayşe, Burcu, Cihat, Engin, Hasan, Mustafa, Tuba, and many others, who so generously shared their knowledge of their language with me. Special thanks are due to my bilingual assistant Nermin Merdanoğlu for her deep insights into the differences between Turkish and TID, and to Kerem Erkan for some excellent video data. The work of the research group is supported by university funding from Anadolu University under project number AÜAF 013084. My research on sign language typology is funded by the German Science Foundation (DFG) under the Emmy-Noether post-doctoral research scheme. The Research Centre for Linguistic Typology at La Trobe University, Melbourne, supported the field trip to Turkey.

\section{References}

Aikhenvald, A.Y. (2000). Classifiers: A typology of noun categorization devices. Oxford: Oxford University Press.

Antzakas, K. (forthcoming). "The use of head movements of negation in Greek Sign Language." Manuscript, City University, London.

Aronoff, M., I. Meir \& W. Sandler (2000). "Universal and particular aspects of sign language morphology." University of Maryland Working Papers in Linguistics, 10:1-33.

Baker-Shenk, C. \& D. R. Cokely (1996). American Sign Language: A teacher's resource text on grammar and culture. Washington, D. C.: Gallaudet University Press.

Banerjee, H.C. (1928). "The sign language of deaf-mutes." Indian Journal of Psychology 3: 69-87.

Bergman, B. (1995). "Manual and nonmanual expression of negation in Swedish Sign Language." In H. Bos \& T. Schermer (eds.), Sign language research 1994: Proceedings of the fourth European congress on sign language research, Munich, September 1-3, 1994, pp. 85-103. Hamburg: Signum.

Berthiaume, R. \& J. Rinfret (2000). La négation en langue des signes québécoise (LSQ). Manuscript, Groupe de recherche sur la langue des signes québécoise, Université du Québec à Montréal.

Coerts, J. (1992). Nonmanual grammatical markers. An analysis of interrogatives, negations and topicalizations in Sign Language of the Netherlands. Doctoral dissertation, Universiteit van Amsterdam.

Dixon, R.M.W. \& A.Y. Aikhenvald (2002). “Word.” In R.M.W. Dixon \& A. Y. Aikhenwald (eds.), Word: A cross-linguistic typology. Cambridge: Cambridge University Press.

Emmorey, K. (2003). Perspectives on classifier constructions in sign language. Mahwah, NJ: Lawrence Erlbaum. 
Kyle, J., G. Pullen, L. Allsop \& P. Wood (1985). "British Sign Language in the British Deaf community." In W. Stokoe \& V. Volterra (eds.), SLR '83. Proceedings of the third international symposium on sign language research, Rome June 22-26, 1983, pp.315-323. Silver Spring, MD: Linstok Press and Rome: Istituto di psicologia CNR.

Lindström, E. (2002). Topics in the grammar of Kuot, a non-Austronesian language of New Ireland, Papua New Guinea. Doctoral dissertation, Stockholm University.

Miles, M. (2000). "Signing in the Seraglio: mutes, dwarfs and jesters at the Ottoman Court 1500-1700." Disability \& Society 15(1): 115-134.

Morris, D. (1979). Gestures: Their origins and distribution. London: Cape.

Özyürek, Aslı \& İlkbaşaran, Deniz (2003). TID Website: http://turkisaretdili.ku.edu.tr

Padden, C.A. (1990). "The relation between space and grammar in ASL verb morphology." In C. Lucas (ed.), Sign language research: Theoretical issues, pp. 118-132. Washington, DC: Gallaudet University Press.

Sandler, W. (1999a). "The medium and the message: Prosodic interpretation of linguistic content in Israeli Sign Language.” Sign Language \& Linguistics 2(2): 187-215.

Sandler, W. (1999b). "Cliticization and prosodic words in a sign language." In A.T. Hall and U. Kleinherz (eds.), Studies on the phonological word, pp 223-254. Amsterdam: John Benjamins.

Sutton-Spence, R. \& B. Woll (1999). The linguistics of British Sign Language. An introduction. Cambridge: Cambridge University Press.

Wilbur, R. B. \& B. Schick (1987) "The effects of linguistic stress on ASL signs." Language and Speech 30(4): 301-323.

Zeshan, U. (2000a). Sign Language in Indo-Pakistan: A description of a signed language. Amsterdam: John Benjamins.

Zeshan, U. (2000b). Gebärdensprachen des indischen subkontinents [Sign languages of the Indian subcontinent]. Linguistic research forum 04. Munich: LINCOM Europa.

Zeshan, U. (2002). "Towards a notion of "word" in signed languages." In R.M.W. Dixon \& A.Y. Aikhenwald (eds.), Word: A cross-linguistic typology. Cambridge: Cambridge University Press.

Zeshan, U. (2003). “'Classificatory' constructions in Indo-Pakistani Sign Language: Grammaticalization and lexicalization processes." In K. Emmorey (ed.), Perspectives on classifier constructions in sign language. Mahwah, NJ: Lawrence Erlbaum.

Zeshan, U. (forthcoming a). "Interrogative constructions in sign languages - Cross-linguistic perspectives." Language 80.1 (2004).

Zeshan, U. (forthcoming b). "Hand, head and face - Negative constructions in sign languages." Linguistic Typology 8.1 (2004). 
Appendix: Manual alphabet in Türk İşaret Dili (Turkish Sign Language)
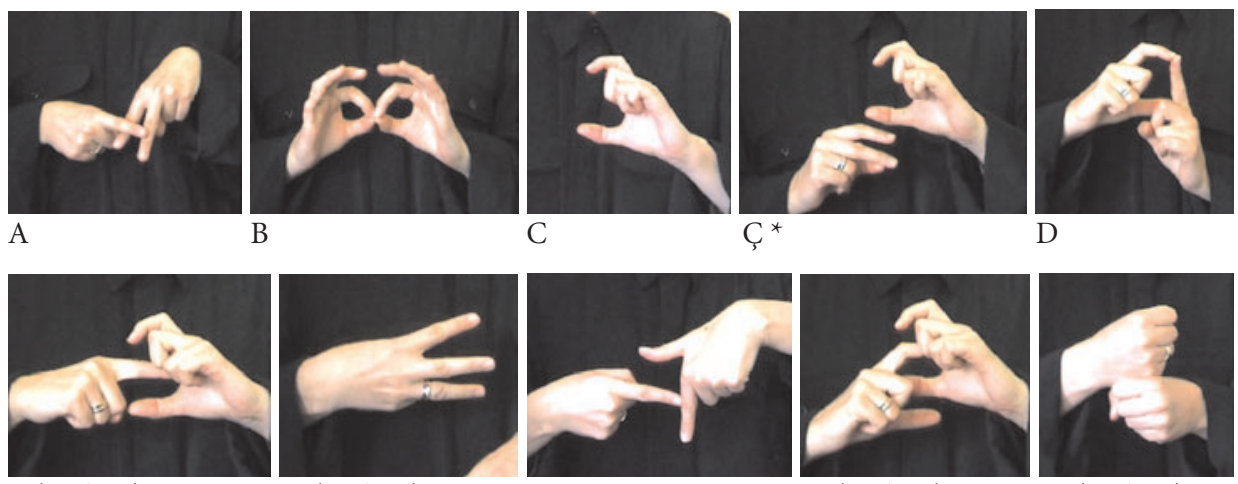

G (variant)
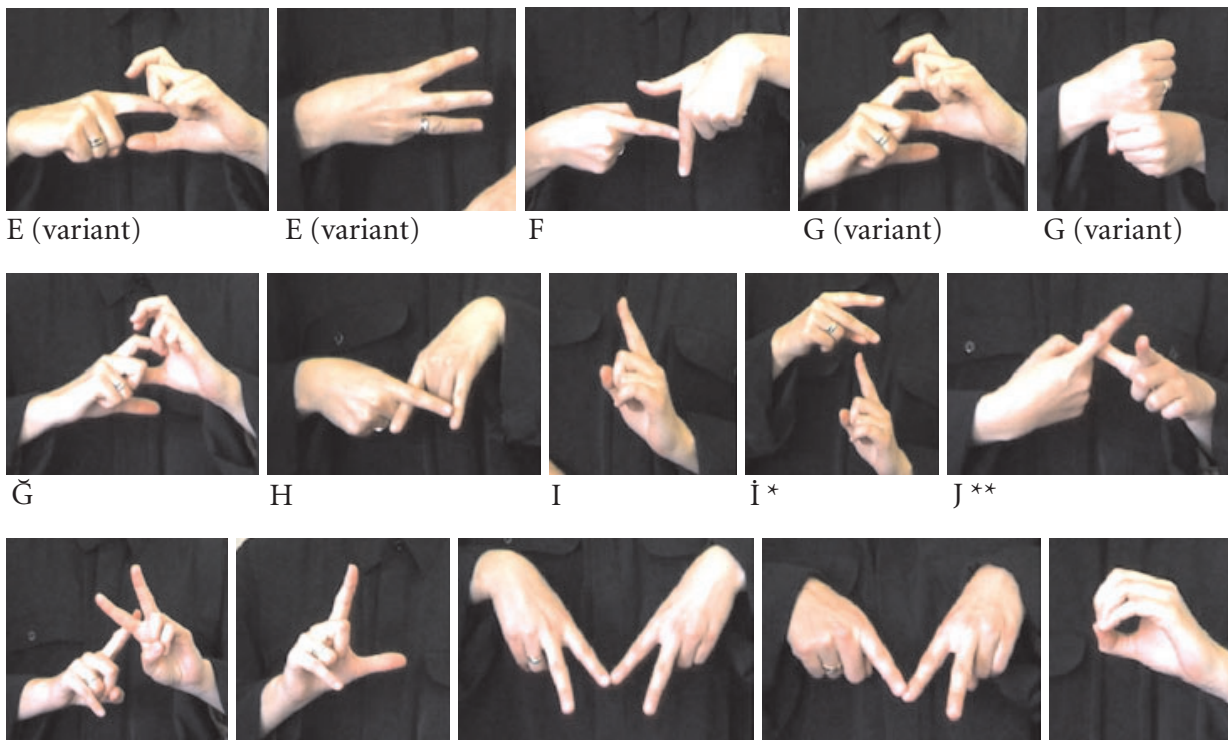

K

L

M

$\mathrm{N}$

$\mathrm{O}$
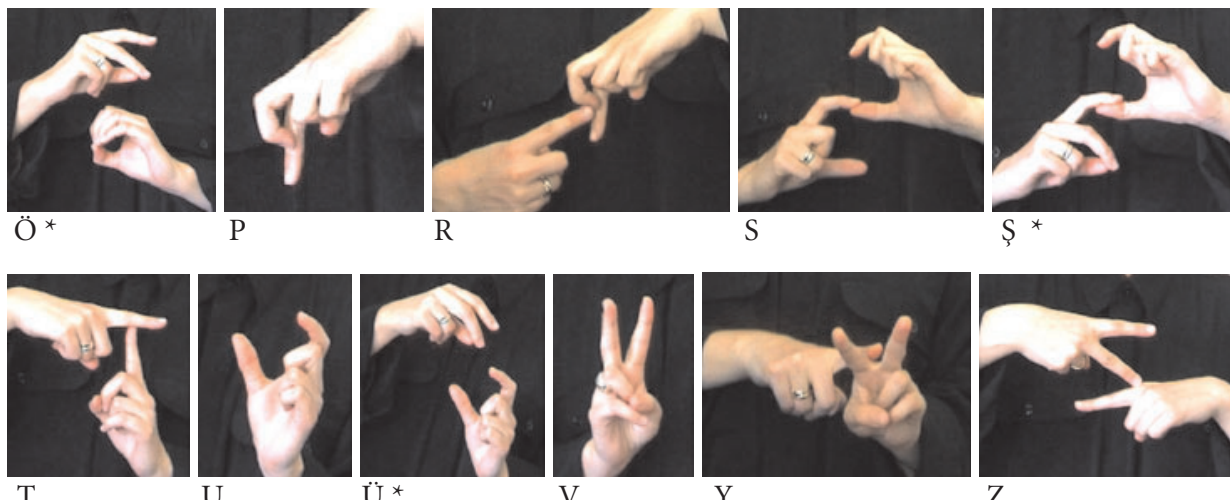

$\ddot{U}^{*}$
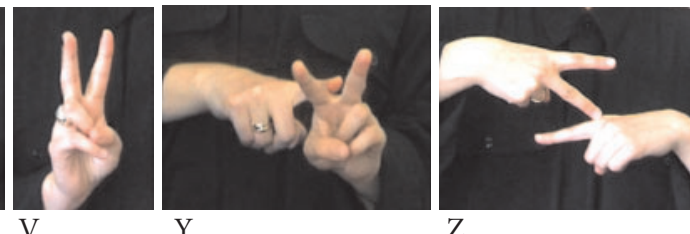

* with finger snapping

** tracing a curve along index finger and thumb 